\title{
SELF-ESTEEM AND TURNOVER INTENTION WITH THE MEDIATING EFFECT OF JOB SATISFACTION: A CASE OF STRUCTURAL CHANGE IN BANKING SECTOR OF PAKISTAN
}

\author{
Noreen Hassan Syed, Department of Business Administration, University of Sindh Jamshoro, Pakistan \\ Nizamuddin Channa, Department of Business Administration, University of Sindh Jamshoro, Pakistan \\ Imamuddin Khoso, Department of Business Administration, University of Sindh Jamshoro, Pakistan
}

dx.doi.org/10.18374/IJBR-20-3.2

\begin{abstract}
Purpose: Greater level of uncertainty and insecurity may pose greater threat to change implementation. In such situation, employee's self-esteem is a key for successful change implementation. Therefore, this study aims to test how personality trait self-esteem improves job satisfaction and help in employee retentionDesign / methodology: A cross sectional study design where data collected once from employees of MCB Bank undergoing a merger with NIB in Pakistan. A survey technique used to collect data applying convenience non-random sampling technique. A total of 350 responses were analyzed through structural equation modeling using Smart PLS.Findings: It was found that self-esteem positively associated to job satisfaction. Job satisfaction negatively related to turnover intention and mediated the link between self-esteem and turnover intention. Research limitations: Major limitation of this study is that it has collected data at single point of time, which may hamper predictive power of the findings. Self-esteem as a personality trait has gradual effects on employee behaviors, thus it would be better to tap these effects in a time lagged study. Practical implications: Leaders and policy makers of the banks need to understand that employee's personality traits affect employee attitudes and thus are relevant during times of organizational changes. Therefore, there is need to enhance employee confidence and self-esteem by creating a supportive work environment in order to retain quality employees in critical times like mergers. Originality / value: This study is unique in a sense it has incorporated that employee developing their confidence,, morale, acceptance and perception level, regarding change experience such as satisfaction with the job as an important mediating mechanism, which deal and overcome emotional response of an individual who prefer to leave the organization at the time of change.
\end{abstract}

Keywords: Self Esteem, Job Satisfaction, turnover intention, Merger and Acquisition 